\title{
Applying the polluter-pays principle to rail: Environmental differentiation of rail access charges
}

\author{
Aleix Pons-Rigat \\ Researcher, CENIT - UPC BarcelonaTech, Spain \\ Mateu Turró \\ Full professor, UPC BarcelonaTech, Spain \\ Lluís Ubalde \\ Project Manager, CENIT - UPC BarcelonaTech, Spain
}

\begin{abstract}
Environmental charges to rail service operators are still at an early stage of implementation in Europe. Current schemes are dissimilar and most of them have a very limited scope or do not provide effective incentives to abate environmental impacts. This is due to several practical difficulties in implementing internalisation pricing schemes in the railway sector.
\end{abstract}

The first difficulty arises from the lack of internalisation in other transport modes and the small competitive margin of railways. Increasing the overall level of rail charges could affect their survival. A second difficulty is due to the uncertainties in the valuation of external costs and in the establishment of the optimal level of charges. On top of that, the imperfect competition in the rail market and its operational and financial rigidities imply that pricing decisions could be unfair and produce undesired demand effects. These difficulties should not prevent, however, advancing towards the application to rail of adequate charging methods for its environmental costs.

This paper addresses the problem of setting environmentally differentiated rail charges through an analytical approach. A generalised formulation is developed that sets the level of charges as a function of the degree of internalisation in other modes. Then, the optimal tradeoff in the level of differentiation is assessed to extract general guidelines. Based on this, both the derived overall costs and benefits and the impacts on each agent are quantified.

\section{INTRODUCTION}

Since the approval of the European Directive 91/440/ECC, the separation of the infrastructure management (non-competitive part) from the railway operation (competitive part) has been compulsory, at least in accounting terms. This division requires the introduction of rail access charges for the use of the infrastructure. The European Directive 2001/14/EC and its subsequent recast Directive 2012/34/EC determine that these charges should be based on 'costs directly incurred as a result of operating the train service'. This means that rail operators should be charged for the marginal cost of track maintenance and other services derived from the operation but also, according to the legislation, the caused external costs of environmental impacts, accidents and congestion may be introduced into the pricing scheme. Nonetheless, it is stated that external costs charges for railways should not result in an increase of the overall revenue accruing to the infrastructure manager unless 
a comparable pricing scheme for external costs is applied to competing modes. In this sense, the use of pure bonus or a neutral bonus-malus scheme to internalise external costs emerges as a suitable pricing option for railways when other modes do not completely internalise the externalities they generate.

Regarding the environmental external costs, some countries in Europe have introduced a differentiation of charges that accounts for noise and air pollution impacts of the railway operation. However, as described by Pons-Rigat et al. (2016), the implementation is still limited and the current schemes have a considerable room for improvement to effectively incentivise the abatement of noise and air pollution impacts. This is due to several difficulties in transferring the theoretical principles of pricing for environmental externalities into a practical pricing scheme.

This paper is focused on dealing with these difficulties by providing an analytical approach to the problem of setting environmentally differentiated rail access charges. It is structured as follows. Section 2 presents the current caveats. The basic theoretical principles are described in Section 3. Based on this, Section 4 presents a model to determine the level of charges, whereas Section 5 deals with the decision on the degree of differentiation. Finally, the economic impacts on each stakeholder are assessed in Section 6 and general conclusions are drawn in Section 7.

\section{CURRENT DIFFICULTIES}

The main problems to be tackled are: 1) optimally differentiating charges according to environmental impacts appraisals; 2) ensuring fair and efficient intermodal competition; and 3 ) allocating incentives to all stakeholders in a cost-effective way.

\subsection{Differentiation of charges}

According to the Pigouvian framework for pricing externalities (Pigou, 1920), to maximise social efficiency, environmental taxes should be equal to the marginal environmental benefit, i.e., the socioeconomic valuation of gains due to the reduction of the environmental impact. Despite multiple studies on the subject ${ }^{1}$, they still show a significant level of uncertainty in their economic valuation and an insufficient level of disaggregation. Moreover, in the case of railways much less research has been conducted in comparison to other modes. Whereas air pollution costs can be estimated with an acceptable precision, noise costs are much more difficult to handle because of the non-linearity nature of its effects (logarithmic scale) and the subjectivity of noise annoyance. Nevertheless, the social welfare gains derived from any internalisation scheme are rather insensitive to errors in estimating marginal environmental costs (Heine et al., 2012; Rabl et al., 2005). According to this, charges should be differentiated in terms of environmental costs even if the cost estimates are relatively imprecise.

1 See e.g. Andersson and Ögren (2013); INFRAS and IWW (2004); Ricardo-AEA et al. (2014) 
Furthermore, the essential issue of how to transfer external costs to a realistic pricing system with an optimal degree of pricing complexity is still unsolved (Nash and Matthews, 2005). In practice, the marginal environmental cost must be used as the background for the establishment of several discrete categories for which the same charging criteria are used. The higher the number of categories, the closer the charging scheme could be to the marginal cost. Operators and users' behaviour will be closer to the socially optimal behaviour with further differentiation, as market signals become more precise and include a wider range of abatement possibilities.

On the other hand, the transaction costs of implementing an environmental pricing scheme inevitable increase with the degree of differentiation. The three main sources of transaction costs are: a) the administrative costs of the control and management system; b) the costs of data collection; and c) the loss of sensitivity of people and organisations with higher levels of pricing complexity. So, a clear trade-off appears when defining an optimal level of differentiation.

\subsection{Fair and efficient competition}

Another difficulty is that the context of imperfect competition and asymmetric information in the railway market requires taking into account the downstream effects (in users' tariffs) of the charging system (Meunier and Quinet, 2012). In the context of the rail market, where most operators are either monopolies or have a high market power, rail operators will most likely transfer all or part of the environmental charges and the eventual abatement costs to final users through tariff increases. This can reduce the effectiveness of incentives and may have counterproductive effects on demand if competing modes are not adequately charged (Matthews et al., 2009). These 'boundary effects' on demand and modal split ought to be minimised by harmonising the level of environmental internalisation across the transport modes. This means that any decision on rail charging should be related to what is applied to the other transport modes and even to other sectors.

On the other hand, the regulatory, operational, and financial rigidities of the railway market severely affect the potential responses of the operators and, in turn, the effectiveness of the environmental pricing scheme. It also raises fairness issues when comparing rail services subject to different regulatory or contractual conditions.

\subsection{Allocation of incentives}

The responsibility for an environmental impact is usually shared by many agents (or sources of pollution), which control different decision variables affecting the final impact. Therefore, in theory, the generated external costs should be shared among the agents that have room for manoeuvre to reduce the impact; i.e. railway undertakings should only be charged for the proportion of environmental costs that results from their decisions. However, splitting external costs may not be suitable for incentivising the adoption of abatement measures. 
For example, the case of an operator running a diesel train on a non-electrified line poses a difficult question on how to allocate air pollution costs. If he is not charged for the full cost of air pollution, he will not have enough incentive to operate cleaner or more efficient trains. On the other hand, the infrastructure manager should also be charged for the full air pollution costs to perceive the required incentive for electrification. But, should both be charged for the full external costs, the result would be clearly inefficient in terms of social welfare.

\section{BASIC PRINCIPLES}

The Pigouvian framework provides a first-best pricing solution to reach an optimal environmental abatement. It will be used as a reference in this analysis. This is illustrated in Figure 1. Marginal abatement costs ( $c$ in Figure 1a) increase with the level of abatement (e.g. Siebert, 2004). On the other hand, marginal environmental costs savings ( $e$ in Figure 1a) can be deemed constant with the level of abatement of air pollution impacts (Heine et al., 2012), whereas in the case of noise this assumption would be less reasonable due to the logarithmic character of its effects on people. The potential social welfare gain $(\Delta S W$, represented by the shaded area between $e$ and $c$ curves in Figure 1a) will be the environmental costs savings minus the abatement costs. Then, if marginal environmental charges discounts $(t$ in Figure 1a) are set equal to marginal environmental costs savings, the rail operator will perform abatement measures up to the optimal level $(A *)$ where marginal benefits equal marginal costs. Under these pricing conditions, private profit and social welfare maximisation will be aligned.

Figure $1 \mathrm{~b}$ shows the same scheme in accumulated terms (capital letters indicate integrated magnitudes). A certain rail service will have an initial level of abatement $A_{o}$ and charge discount $T_{o}$, while the most polluting services will have the minimum level of abatement $A_{\min }$ and so the maximum environmental cost $E_{\max }$.

In practice the potential social welfare gains of an environmental charging system will have some losses deriving from its practical implementation, the main ones being errors in environmental damage appraisal, transaction costs, and misalignments of incentives.
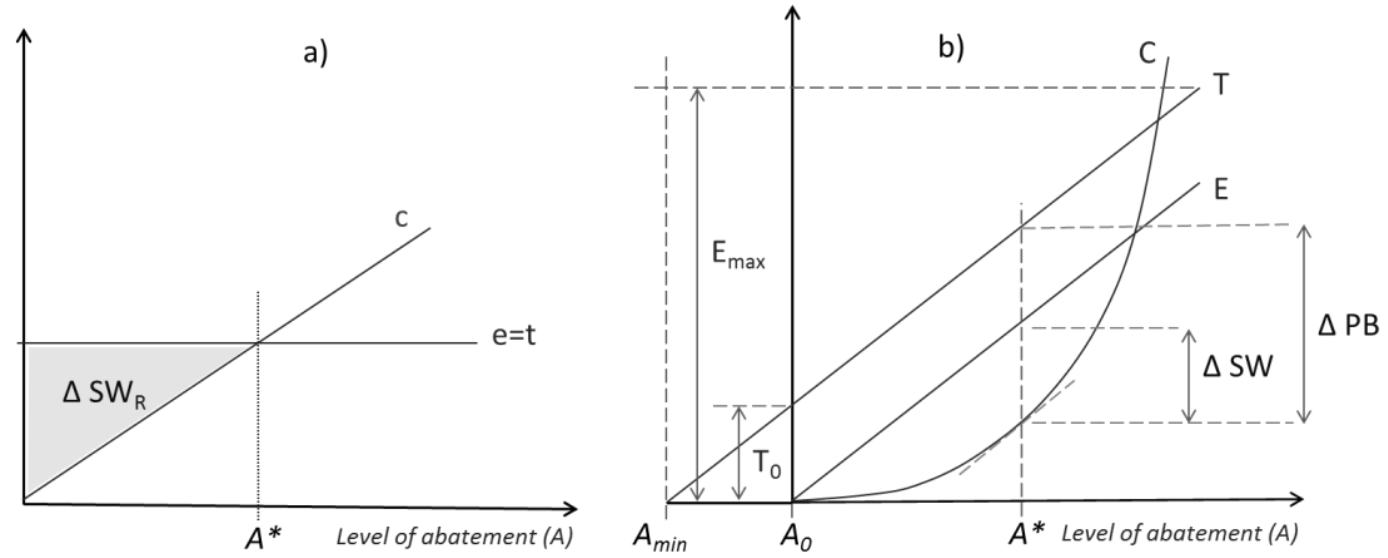

Figure 1 - Basic scheme of analysis in marginal (a) and accumulated (b) terms 
To model the problem in a tractable way a single abatement dimension is considered. Also, the marginal abatement cost function is deemed to be linear whereas the marginal environmental costs savings are assumed to be constant. One may argue that, in fact, marginal abatement costs depend, in turn, on the pricing and regulatory context (Parry et al., 2014) but this will not be considered in our simplified analysis.

\section{LEVEL OF CHARGES}

In the former model, as long as the $T$ curve is parallel to the $E$ curve the social welfare maximising point will be the same as the private benefit maximising point. Hence, the absolute value of the charge does not affect the optimal abatement point reached but only the difference between the social welfare $(\triangle S W)$ and the private benefit $(\triangle P B)$. This defines the basic structure of the proposed charge if we want to provide incentives to reach the optimal abatement level. The necessary condition is that the marginal discount in the charge equals the marginal reduction in environmental damage. If we call $K$ the total environmental charge (and so $k$ in marginal terms), this is:

$$
k=-t=-e \rightarrow K=\text { constant }-T \rightarrow K=\text { constant }-T_{o}-E
$$

If the pricing system is to be generally applied to a certain set of rail services, all charge discounts need to have a 'zero' point where no bonus is applied. The easiest and most effective way to proceed is to set the 'zero for bonuses' for the most polluting service. Then, a pure bonus charge $\left(K_{\text {bonus }}\right)$ and a pure malus charge $\left(K_{\text {malus }}\right)$ would be respectively:

$$
\begin{gathered}
K_{\text {bonus }}=-T \\
K_{\text {malus }}=E_{\max }-T
\end{gathered}
$$

A generalised expression that integrates the bonus and malus concept as a function of a parameter $\alpha \in[0,1]$ can be expressed as:

$$
K=(1-\alpha) \cdot K_{\text {bonus }}+\alpha \cdot K_{\text {malus }}=\alpha \cdot E_{\max }-T
$$

The previous expression is general because for $\alpha=0$ it is a pure bonus while for $\alpha=1$ it is a pure malus. As shown in Figure 2, in the case of malus, $\alpha \cdot E_{\max }$ is the maximum surcharge to be paid by rail operators. In the bonus region, $\alpha \cdot E_{\max }$ can be understood as the minimum level to be reached to start getting a bonus. For the abatement level $A_{e}$ neither a malus nor a bonus is paid.

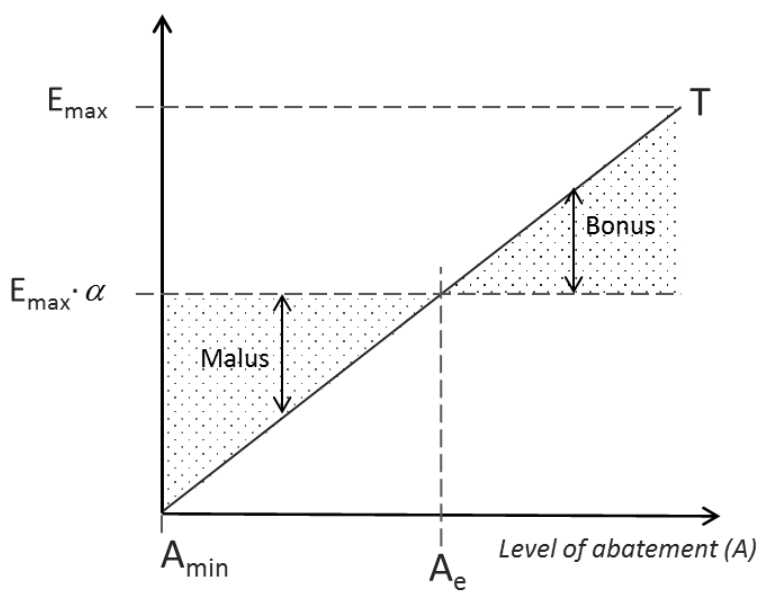

Figure 2 - Scheme of the proposed charging scheme as a function of alpha 
At this point, the only decision to be made is what should be the value of alpha. In this methodology we propose to set alpha at the average internalisation ratio of competing modes. This ensures that no rail service is paying more for environmental costs than the average of the competing modes. Hence, only environmentally non-competitive rail services are paying a malus. Using this approach, efficient incentives are provided to railway undertakings for abating environmental impacts while ensuring a fair competition with the rest of transport modes, i.e., a level of charges that does not damage the competitiveness of rail transport.

\section{DEGREE OF DIFFERENTIATION}

The optimal level of differentiation should be obtained taking into account the trade-off between the precision in the provision of incentives and the simplicity of the charging system. The net social welfare gains $\left(\Delta S W_{\text {net }}\right)$ will be then:

$$
\Delta S W_{\text {net }}=\Delta S W^{*}-\operatorname{LSW}(n)-C_{D}(n)
$$

where:

$\mathrm{n}$ : number of differentiated categories in the environmental charge

$\Delta S W^{*}$ : Optimal social welfare gains in first-best conditions $\left(\Delta S W^{*}=E^{*}-C^{*}\right)$

$\operatorname{LSW}(n)$ : Loss in social welfare caused by the discretisation of the environmental charge. $\left(\frac{\partial L S W}{\partial n}<0\right)$

$C_{D}(n)$ : Costs of differentiation (transaction costs and loss of effectiveness due to complexity) $\left(\frac{\partial C_{D}}{\partial n}>0\right)$

Therefore, the following problem should be solved:

$$
\min _{n}\left[\operatorname{LSW}(n)+C_{D}(n)\right]
$$

An analytical model is developed to quantify this trade-off based on the following assumptions:

i. Unidimensional problem: A single abatement measure is considered

ii. Charges are discrete according to ranges of the abatement process

iii. All ranges have the same length (L) and imply a certain number of categories (n)

iv. Both the environmental benefits and the marginal abatement costs are linear

In the first place, the function $\operatorname{LSW}(n)$ should be evaluated. Figure 3 illustrates the problem. 


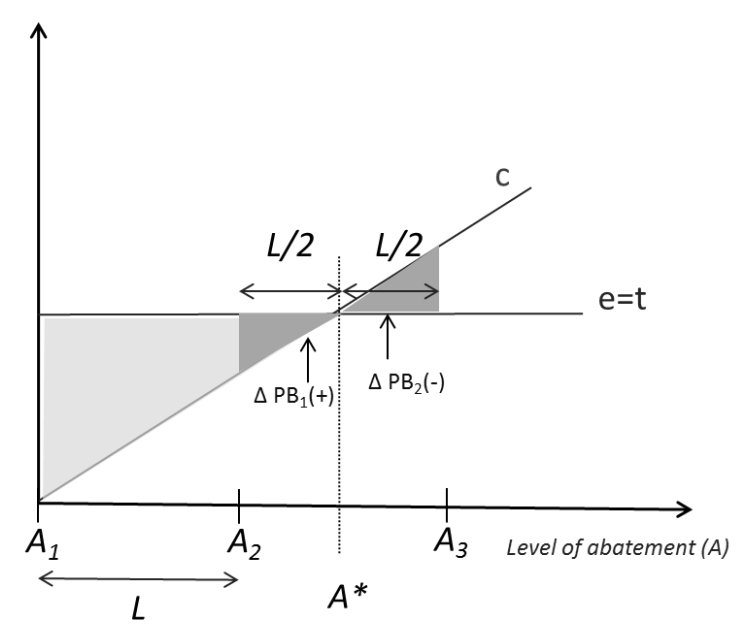

Figure 3 - Loss of social welfare due to the discretisation of the charge

In a case of a random discretisation of the charges (with an equal range length $\mathrm{L}$ ), the maximum distance to the optimum abatement point will be reached when the optimal is exactly in the middle of the charge range. In this case, the operator will be indifferent between the low and the high end of the range $\left(A_{2}\right.$ and $A_{3}$ in Figure 3$)$. Then the average error will be:

$$
\delta(n)=\frac{L}{4}=\frac{L_{T}}{4 n}
$$

Where $L_{T}$ is the total length of the abatement range. The derived loss in social welfare is represented by the darker triangles in Figure 3. Therefore, the average loss in social welfare can be determined as:

$$
\operatorname{LSW}(n)=\frac{L_{T}^{2}}{32 n^{2}} \cdot \frac{d^{2} C}{d R^{2}} \sim n^{-2}
$$

From the result above it can be concluded that the marginal benefit of further differentiation decreases with increased differentiation. Then if differentiation costs are convex, the number of categories should be small. Otherwise, the optimal number of differentiation categories will depend on the shape of the differentiation cost function.

\section{ECONOMIC IMPACTS}

From the provided analytical approach, the long-term economic impacts on each stakeholder when the charging system is implemented can be deduced. This is shown in Table 1.

\begin{tabular}{|c|c|c|c|}
\hline Infrastructure manager & Rail operators and users & $\begin{array}{c}\text { Society } \\
\text { (non-users) }\end{array}$ & Total \\
\hline $\begin{array}{r}-C_{D}-T_{0}-E^{*} \pm \begin{array}{l}\delta \cdot e \\
+\alpha \cdot E_{\max }\end{array} \\
T_{0}+E^{*}-C^{*}-L S W \\
-\alpha \cdot E_{\max }\end{array}$ & $+E^{*} \pm \delta \cdot e$ & $E^{*}-C^{*}-L S W-C_{D}$ \\
\hline
\end{tabular}

Table 2 - Long-term economic impacts on the relevant stakeholders (Positive sign for benefits and negative sign for costs) 


\section{CONCLUSIONS}

This paper addresses some of the difficulties of implementing a practical environmental differentiation of rail charges through an analytical approach. A formulation is proposed to set the level of charges in a way that proper incentives are provided to rail operators while ensuring a fair and efficient competition with the rest of transport modes. Secondly, the degree of differentiation is analysed to conclude that the benefits of higher differentiation are concave whereas the costs of differentiation should be analysed case by case. Finally, the long-term economic impacts on each stakeholder when the proposed charging scheme is implemented are presented.

\section{REFERENCES}

ANDERSSON, H., ÖGREN, M., 2013. Charging the Polluters. A pricing model for road and railway noise. J. Transp. Econ. Policy 47, 313-333.

HEINE, D., NORREGAARD, J., PARRY, I., 2012. Environmental Tax Reform: Principles from Theory and Practice to Date, IMF Working Papers.

INFRAS, IWW, 2004. External Cost of Transport. Update study, IWW. Zurich/Karlsruhe.

MATTHEWS, B., EVANGELINOS, C., JOHNSON, D., MEUNIER, D., 2009. Impacts and incentives of differentiated rail infrastructure charges in Europe - focus on freight. Eur. Transp. 43, 83-112.

MEUNIER, D., QUINET, E., 2012. Applications of transport economics and imperfect competition. Res. Transp. Econ. 36, 19-29.

NASH, C., MATTHEWS, B., 2005. Transport Pricing Policy and the Research Agenda. Res. Transp. Econ. 14, 1-18.

PARRY, I.W.H., EVANS, D., OATES, W.E., 2014. Are energy efficiency standards justified? J. Environ. Econ. Manage. 67, 104-125.

PIGOU, A.C., 1920. The Economics of Welfare, Macmillan. ed. London.

PONS-RIGAT, A., TURRÓ, M., SAURÍ, S., UBALDE, L., 2016. Environmental rail charges in Europe: A review. Barcelona.

RABL, A., SPADARO, J. V., VAN DER ZWAAN, B., 2005. Uncertainty of air pollution cost estimates: To what extent does it matter? Environ. Sci. Technol. 39, 399-408.

RICARDO-AEA, DIW ECON, CAU, 2014. Update of the Handbook on External Costs of Transport. Brussels.

SIEBERT, H., 2004. Economics of the environment. Theory and policy, Sixth edit. ed. Springer, Berlin, Heidelberg, New York. 